\title{
Twist1 promotes astrocytoma development by stimulating vasculogenic mimicry
}

\author{
WEI CAO ${ }^{1}, \mathrm{CAN}^{\mathrm{XU}}{ }^{1}, \mathrm{XINXING} \mathrm{\textrm {LI } ^ { 2 } \text { and XIANGHONG YANG }}{ }^{1}$ \\ Departments of ${ }^{1}$ Pathology and ${ }^{2}$ Neurosurgery, Shengjing Hospital of China Medical University, \\ Shenyang, Liaoning 110004, P.R. China
}

Received May 19, 2018; Accepted April 17, 2019

DOI: $10.3892 / \mathrm{ol} .2019 .10380$

\begin{abstract}
Astrocytomas are one of the most vascularized types tumor in human cancers. Micro-vascular proliferation is an important factor for the classification of astrocytoma. Vasculogenic mimicry (VM) is a novel tumor vascular model that develops independently of endothelial cells, and serves an important role in astrocytoma. Twist family bHLH transcription factor 1 (Twist1) is able to regulate the formation of VM; thus in the present study, the expression and importance of Twist1 was studied in astrocytoma tissues. The present study confirmed that the expression of Twist1 was associated with the grade of astrocytoma. Twist1 promotes the formation of VM and the development of astrocytomas, and may also regulate the formation of VM via vascular endothelial-cadherin and matrix metalloproteinase-9.
\end{abstract}

\section{Introduction}

Astrocytoma is reportedly one of the most vascularized types of tumor, and angiogenesis is important for the growth and metastasis of astrocytomas (1). Anti-angiotherapy for endothelial cells has been used successfully in $\sim 50 \%$ of patients with astrocytoma; however as a result of resistance to current treatments (2-5), it is necessary to establish novel therapeutic targets.

Vasculogenic mimicry (VM) is a novel pattern of neovascularization that differs from the classical tumor angiogenesis pathway, and does not depend on endothelial cells (6). A number of studies have reported that VM exists in melanoma, inflammatory breast cancer, colorectal cancer, liver cancer, prostate cancer and other malignant tumors $(7,8)$. VM is not only associated with tumor growth and metastasis, but also with the prognosis of disease (9), suggesting a poor prognosis

Correspondence to: Professor Xianghong Yang, Department of Pathology, Shengjing Hospital of China Medical University, 36 Sanhao Street, Shenyang, Liaoning 110004, P.R. China E-mail: xhyang4933@vip.sina.com

Key words: astrocytoma, Twist1, vascular endothelial-cadherin, matrix metalloproteinase-9, vasculogenic mimicry for patients with astrocytoma. A previous study confirmed that VM was involved in the angiogenesis of astrocytomas and associated with tumor differentiation (10).

In recent years, a number of studies have demonstrated that twist family bHLH transcription factor 1 (Twist1) is highly expressed in various types of cancer, including bladder, gastric, nasopharyngeal and prostate carcinoma, in addition to breast cancer and synovial sarcoma. The role of Twist 1 in the development of cancer involves a variety of mechanisms, including the regulation of tumor cell growth, differentiation, inhibition of apoptosis, increased resistance to chemotherapy and the promotion of tumor angiogenesis (11-15). It has been demonstrated that Twist1 downregulates the expression level of epithelial E-cadherin and upregulates that of vascular endothelial (VE)-cadherin and matrix metalloproteinase (MMP)-9/2 to promote VM formation in hepatoma cells (16-19). However, the number of studies surrounding VM formation in astrocytomas remains limited.

The role of Twist1 in astrocytomas was examined in the present study and the association between Twist1 and VM was evaluated. It was concluded that Twistl may induce the progression of astrocytomas by stimulating VM.

\section{Materials and methods}

Samples. A total of 108 cases of human astrocytoma were selected from the Surgical Department in Shengjing Hospital, China Medical University between June 2007 and July 2013. These cases included 57 males and 51 females, with a mean age of 48 years (range, 24-76 years). According to the 2007 World Health Organization (WHO) histological classification criteria (20), 31 cases were diffuse astrocytoma (WHOII), 47 cases were anaplastic astrocytoma (WHOIII grade), and 30 cases were WHOIV grade glioblastoma. None of the patients were given chemo- or radiotherapy prior to surgery, nor did they receive postoperative routine radiotherapy or chemotherapy. All specimens were fixed using 4\% neutral formaldehyde at $4^{\circ} \mathrm{C}$, overnight, embedded in paraffin, sectioned at $5 \mu \mathrm{m}$ and routinely stained with hematoxylin and eosin for diagnosis at room temperature. The specific steps are as follows: The slices were placed in an oven at $60^{\circ} \mathrm{C}$ for $2 \mathrm{~h}$ and then stained. After dewaxing to water, the hematoxylin dye solution was dyed for 2-3 min, washed with tap water, washed with $1 \%$ hydrochloric acid alcohol solution for several 
seconds, washed with tap water, dyed with eosin dye solution for $1 \mathrm{~min}$, washed with tap water, and sealed with neutral gum. The samples were examined by light microscopy (magnification, x100 and x400; Leica DM2500M; Leica Microsystems $\mathrm{GmbH}$ ) in five-randomly selected visual fields. The protocols were approved by the Ethics Committee of General Hospital of Shengjing Hospital (China Medical University), and all patients signed informed consent prior to surgery.

Immunohistochemistry. The specimens were fixed in a $4 \%$ neutral formalin solution at $4^{\circ} \mathrm{C}$, overnight, embedded in paraffin and cut into $5 \mu \mathrm{m}$ slices. The paraffin sections were subsequently dewaxed in water, and incubated with $3 \% \mathrm{H}_{2} \mathrm{O}_{2}$ for $10 \mathrm{~min}$ at room temperature. The sections were incubated with 3\% goat serum (cat. no. C0265; Beyotime Institude of Biotechnology, Shanghai, China) at room temperature for $10 \mathrm{~min}$, and subsequently incubated with the following primary antibody at $4^{\circ} \mathrm{C}$ overnight: Primary antibodies against Twist 1 (cat. no. ab50887; 1:1,000), VE-cadherin (cat. no. ab33168; 1:800) and MMP-9 (cat. no. ab38898; 1:1,000) purchased from Fuzhou Maxin Biological Technology Development Co., Ltd. Sections were incubated with streptavidin-horseradish peroxidase (HRP) kit (Fuzhou Maxin Biological Technology Development Co., Ltd.) for 10 min, stained with 3,3'-diaminobenzidine (DAB; cat. no., kit-0017; Fuzhou Maxin Biological Technology Development Co., Ltd.), according to the manufacturer's protocols and then counter-stained with hematoxylin for 2-3 min at room temperature and sealed with neutral gum. The samples were examined by light microscopy (magnification, x400; Leica DM2500M; Leica Microsystems GmbH) in five-randomly selected visual fields. Immunohistochemical results were assessed using histological score (HSCORE) (21). The intensity of staining was graded according to the following criteria: 0 , no staining; 1 weak staining (light yellow); 2 , moderate staining (yellow-brown); 3 , strong staining (brown). The staining index (SI) was calculated as the product of staining intensity score and proportion of positive tumor cells. This study assessed the indicated protein expression in IHC-stained tumor sections determined by SI scores as $0,1,2$, $3,4,6$, and 9 .

VM assessment. Immunohistochemical staining was carried out against CD34 (ab54208, 1:1,000, Abcam) according to the method (22). Periodic Acid Schiff (PAS) (cat. no. C0730; 1:1,000; Tianjin Bai Hao Biological Technology Co.) staining was performed on the paraffin-embedded samples for $15 \mathrm{~min}$ at room temperature, following incubation with $3 \%$ $\mathrm{H}_{2} \mathrm{O}_{2}$ for $10 \mathrm{~min}$ at room temperature. Double-stained tissue sections were observed with light microscopy (magnification, x100; Leica DM2500M; Leica Microsystems GmbH), in five-randomly selected visual fields, and $\mathrm{PAS}^{+} / \mathrm{CD}^{-} 4^{-}$cells were identified as VM vessels.

Cell culture. U251 and SHG44 cells (National Infrastructure of Cell Line Resource) were cultured in Dulbecco's Modified Eagle's medium (DMEM) and RPMI-1640 medium containing 10\% FBS (all Invitrogen; Thermo Fisher Scientific, Inc.), respectively; HUVECs (National Infrastructure of Cell Line Resource) were cultured in RPMI-1640 medium containing 15\% FBS and Endothelial Cell Growth Supplement (Invitrogen;
Thermo Fisher Scientific, Inc.). All cells were cultured at $37^{\circ} \mathrm{C}$ with $5 \% \mathrm{CO}_{2}$.

Three-dimensional (3D) cell culture and the formation of an in vitro cavity structure. A total of $50 \mu 1$ Matrigel was plated into each well of a 96-well plate. After incubation for $2 \mathrm{~h}$ at $37^{\circ} \mathrm{C}, 5 \times 10^{4}$ cells were added into each well with $100 \mu \mathrm{l}$ of the appropriate medium. After $48 \mathrm{~h}$ of culture, five fields were visualized using an inverted phase contrast microscope (magnification, x100). The formation of cell tubules was observed, and images were captured and counted.

Transfection. The transfection was carried out by Lipofectamine ${ }^{\circledR} 2000$ (Beyotime Institute of Biotechnology, Shanghai, China). Lipofectamine ${ }^{\circledR} 2000$ were mixed with small interfering (si)RNA or plasmids at room temperature for $20 \mathrm{~min}$, added into cells and transfected for $24 \mathrm{~h}$. Si-Twist1 and the corresponding negative control RNA were purchased from Wuhan Crystal Bio Technology Co., Ltd. The RNA interference sequences were as follows: Si-Twist1-1, 5'-CCU GAGCAACAGCGAGGAATT-3'; si-Twist1-2, 5'-GCAAGA UUCAGACCCUCAATT-3'; si-Twist1-3' 5'-GAUGGCAAG CUGCAGCUAUTT-3'; control' 5'-UUCUCCGAACGUGUC ACGUTT-3'. A total of $5 \mu \mathrm{g}$ small interfering RNA or corresponding negative control RNA was transfected into U251 and SHG44 cells. The control group of si-Twist1 was transfected with corresponding negative control RNA (mock group).

A total of $18 \mu \mathrm{g}$ pcDNA3.1-Twist (Invitrogen; Thermo Fisher Scientific, Inc.) was also transfected into U251 and SHG44 cells. The control group of pcDNA3.1-Twist was transfected with empty vector alone (vec group). Untreated cells were also used as a control in these experiments (con group). Follow-up studies were done $48 \mathrm{~h}$ after transfection.

Western blotting. Total protein was extracted from cells by RIPA (Beyotime Institute of Biotechnology). Bicinchoninic acid assay kit (cat. no. 71285-3, Merck KGaA) was used to quantify protein concentration, according to the manufacturer's protocols. A total of $40 \mu \mathrm{g}$ of each protein sample was separated using $10 \%$ SDS-PAGE and transferred to a polyvinylidene difluoride membrane $(70 \mathrm{~V}, 1.5 \mathrm{~h})$. After incubation in $5 \%$ skimmed milk for $2 \mathrm{~h}$ at room temperature the membranes were incubated with the following primary antibodies, purchased from Abcam: Anti-Twist1 (cat. no. ab50581, 1:1,000) anti-VE-cadherin (cat. no. ab119785, 1:1,000) anti-MMP9 (cat. no. ab73734, 1:1,000) $\beta$ actin (cat. no. ab8227, 1:1,000) overnight at $4^{\circ} \mathrm{C}$. The membranes were subsequently incubated with secondary antibodies also purchased from Abcam [Goat anti-rabbit IgG (HRP, ab7090, 1:1,000) and Goat anti-mouse IgG (HRP, ab6789, 1:1,000)] for $2 \mathrm{~h}$ at room temperature. After washing three times with TBS Tween-20, protein bands were visualized with enhanced chemiluminescence reagents (Beyotime Institute of Biotechnology). $\beta$-actin was used as an internal control. Densitometry analysis used Image J 18.0 (National Institutes of Health).

Statistical analysis. All experiments were repeated at least three times. The data were processed by SPSS for Windows 17 statistical analysis software (SPSS, Inc., Chicago, IL, USA). Statistical comparisons were made using one-way analysis of 
A

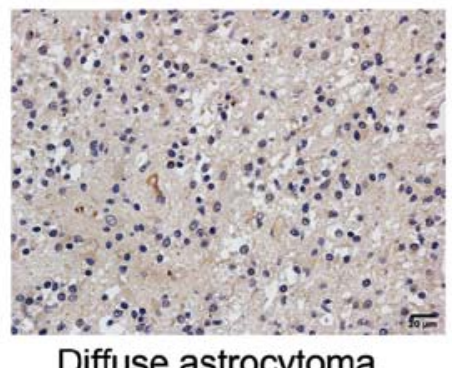

B

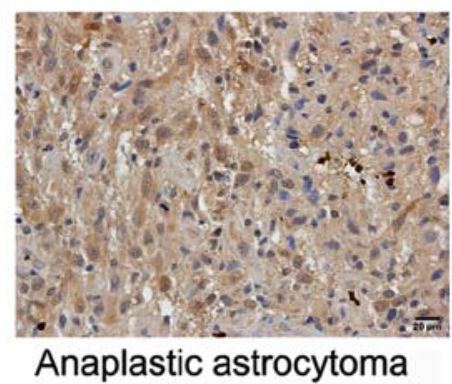

C

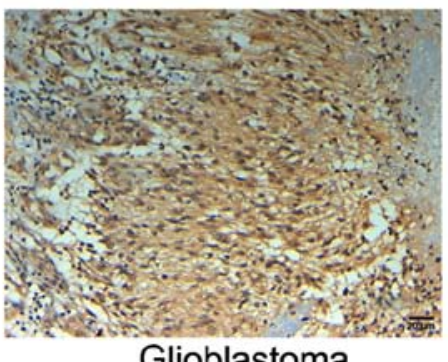

Glioblastoma

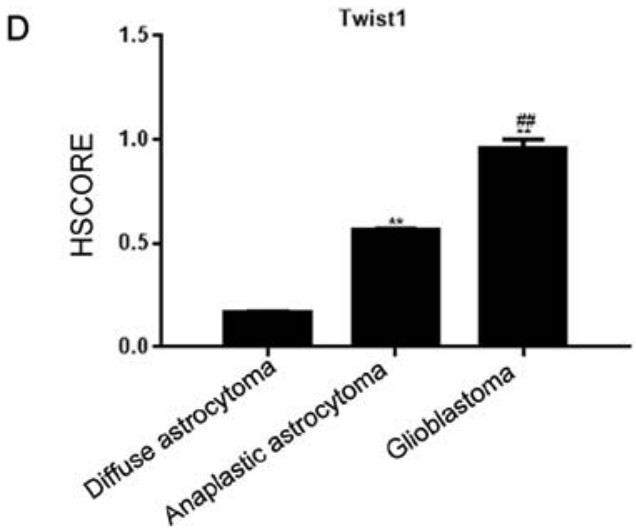

Figure 1. Expression of Twist1 in astrocytoma tissues. (A) Twist1 was weakly expressed in diffuse astrocytomas and localized to the cytoplasm. (B) Twist1 was moderately expressed in anaplastic astrocytomas and localized to the cytoplasm. (C) Glioblastoma tissues exhibited strong, positive Twist1 expression, localized in the nucleus and/or the cytoplasm. Magnification, x200. (D) HSCOREs of diffuse astrocytoma, anaplastic astrocytoma and glioblastoma tissues. ${ }^{* *} \mathrm{P}<0.05$, vs. the diffuse astrocytoma group; ${ }^{\# \#} \mathrm{P}<0.05$, vs. the anaplastic astrocytoma group. Twist, Twist family bHLH transcription factor 1 ; HSCORE, histological score.

variance and Least Significant Difference post hoc test, and associations between Twist1 expression and clinicopathological features, VM formation and the expression of other related proteins were assessed using the $\chi^{2}$ test. $\mathrm{P}<0.05$ was considered to indicate a statistically significant difference.

\section{Results}

Expression of Twistl in astrocytoma tissues. In diffuse and anaplastic astrocytoma tissues, Twist 1 was located in the nucleus, and to a lesser degree in the cytoplasm. The number of positively-stained cells was $16.13 \%$ in diffuse, and $57.45 \%$ in anaplastic astrocytoma tissues (Fig. 1A and B). In the glioblastoma tissue, Twist1 was located in the nucleus and cytoplasm, and demonstrated medium-strong positive expression (the positive rate was 93.33\%; Fig. 1C). The HSCORE is presented in Fig. 1D. Compared with the diffuse and anaplastic astrocytoma tissues, Twist1 was highly expressed in glioblastoma tissues, and the expression level of Twist1 was significantly associated with the WHO astrocytoma classification $(\mathrm{P}<0.05)$, but not with the sex or age of the patients $(\mathrm{P}>0.05$; Table I).

Association between the expression of Twist 1 and the formation of VM. By observing the CD34/PAS double staining of astrocytoma samples, it was demonstrated that most of the vascular structures in the tumor tissues were typical. The blood vessels comprised endothelial cells $\left(\mathrm{CD} 34^{+}\right)$and basement membranes (PAS ${ }^{+}$; Fig. 2A and B). In certain tissues, the VM was composed of CD34- cells and the basement membrane (PAS ${ }^{+}$; Fig. 2B-D). The HSCORE is presented in Fig. 2E. It was demonstrated that out of 108 astrocytoma tissues, 16 cases exhibited VM (11 in glioblastoma and 5 in astrocytoma). Twist1 expression in astrocytoma was significantly associated with VM formation (Table II).

Expression of VE-cadherin and MMP-9 in astrocytomas. In 108 astrocytoma tissues across the 3 different tissue groups, the positive expression rate of MMP-9 was $67.59 \%$ (73 cases; Fig. 3A-C) and the positive rate of VE-cadherin expression was $39.81 \%$ (43 cases; Fig. 3E-G). The HSCORE is presented in Fig. 3D and H. The two proteins were detected in the cytoplasm of tumor cells; VE-cadherin was expressed in vascular endothelial cells. The expression of Twist1 in astrocytomas was associated with that of MMP-9 and VE-cadherin (Table III). Furthermore, the formation of VM was related to that of VE-cadherin and MMP-9 (Table IV).

Formation of an in vitro cavity structure. In order to better detect the angiogenesis of different tumor cells, this study carried out a 3D cell culture. In vitro 3D culture demonstrated that the number of cavity structures in U251 cells notably increased compared with that in SHG44 cells, but was significantly lower compared with HUVECs (Fig. 4A-D).

Twist1, VE-cadherin and MMP-9 expression in U251 and SHG44 cells. The results of western blot analysis demonstrated that the expression of Twist1, VE-cadherin and MMP-9 in the 
Table I. Association between Twist1 expression and clinicopathological features in patients with astrocytoma.

\begin{tabular}{lcccc}
\hline & \multicolumn{2}{c}{$\begin{array}{c}\text { Twist1 } \\
\text { expression }\end{array}$} & & \\
\cline { 2 - 2 } $\begin{array}{l}\text { Patient } \\
\text { characteristic }\end{array}$ & + & - & $\chi^{2}$-value & P-value \\
\hline II & 5 & 26 & 36.924 & $>0.001^{\mathrm{a}}$ \\
III & 27 & 20 & & \\
IV & 28 & 2 & & \\
Sex & & & & \\
Male & 31 & 26 & 0.067 & \\
Female & 29 & 22 & & \\
Age & & & & \\
$>48$ & 33 & 21 & 1.350 & \\
$\leq 48$ & 27 & 27 & & \\
\hline a $<0.05$. Twist1, Twist family bHLH transcription factor $1 ;$ WHO \\
stage, world health organization histological classification grade. \\
\hline
\end{tabular}

Table II. Association between Twist1 expression and the incidence of VM in astrocytomas.

\begin{tabular}{ccrcr}
\hline & \multicolumn{2}{c}{ Twist1 } \\
expression (n) & & & \\
\cline { 3 - 4 } & + & - & $\chi^{2}$-value & P-value \\
\hline+ & 15 & 1 & 11.097 & $0.001^{\mathrm{a}}$ \\
- & 45 & 47 & & \\
\hline
\end{tabular}

${ }^{\mathrm{a}} \mathrm{P}<0.05$. Twist1, Twist family bHLH transcription factor 1 ; VM, vasculogenic mimicry.

SHG44 was significantly downregulated compared with the U251 cell line (Fig. 5A-C).

Effects of Twist 1 on in vitro cavity structure. In vitro 3D culture illustrated that the number of cavity structures in cultured cells decreased as a result of Twist1 silencing. Following Twist1 overexpression, the number of cavity structures increased significantly compared with the control (Fig. 6A and B). Western blotting demonstrated that si-Twist1 was able to inhibit the expression of Twist1, VE-cadherin and MMP-9 in U251 and SHG44 cells. Overexpression of Twist1 promoted a significant increase in the expression levels of these proteins in both cell lines compared with the corresponding control (Fig. 6C and D).

\section{Discussion}

Micro-vessel proliferation is an important factor to consider when grading astrocytomas. Angiogenesis is also a prominent feature of astrocytoma, and is associated with its malignant progression $(23,24)$. Glioblastoma is the highest grade of
Table III. Association between Twist1 expression and MMP-9/ VE-cadherin.

\begin{tabular}{lrrrr}
\hline & \multicolumn{2}{c}{$\begin{array}{c}\text { Twist } 1 \\
\text { expression }\end{array}$} & & \\
\cline { 2 - 3 } Protein & + & - & $\chi^{2}$-value & P-value \\
\hline MMP-9 & 46 & 27 & 5.075 & $0.024^{\mathrm{a}}$ \\
+ & 14 & 21 & & \\
- & & & & \\
VE-cadherin & 34 & 9 & 15.999 & $6.337 \times 10^{-05 a}$ \\
+ & 26 & 39 & & \\
\hline
\end{tabular}

${ }^{a} \mathrm{P}<0.05$. Twist1, Twist family bHLH transcription factor 1 ; MMP, matrix metalloproteinase; VE, vascular endothelial.

Table IV. Association between VM and MMP-9/VE-cadherin in astrocytoma.

\begin{tabular}{lrrrr}
\hline & \multicolumn{2}{c}{ VM } & & \\
\cline { 2 - 3 } Protein & + & - & $\chi^{2}$-value & P-value \\
\hline MMP-9 & 15 & 58 & 5.867 & $0.015^{\mathrm{a}}$ \\
+ & 1 & 34 & & \\
- & & & & \\
VE-cadherin & 12 & 31 & 9.704 & $0.001^{\mathrm{a}}$ \\
+ & 4 & 61 & & \\
\hline
\end{tabular}

${ }^{\mathrm{a}} \mathrm{P}<0.05$. MMP, matrix metalloproteinase; VE, vascular endothelial.

astrocytoma (WHOIV) and is the most vasculogenic malignancy $(25,26)$. In order to increase the effectiveness of clinical treatment, further investigation into the molecular mechanism of astrocytoma angiogenesis is required.

Twistl can promote tumor progression by regulating tumor cell growth, differentiation, drug resistance, angiogenesis and metastasis $(27,28)$. The exogenous overexpression of Twist1 increased the invasive and metastatic capacity of cancer cells by promoting the downregulation of E-cadherin, and the induction of epithelial-mesenchymal transition (EMT) (29). A previous study has indicated that other transcription factors involved in EMT, including transcription factor 7 and lymphoid enhancer-binding factor 1 , are also involved in astrocytoma progression (30). The results of the present study indicated that the expression of Twist1 in glioblastoma was increased compared with that in anaplastic and diffuse astrocytomas, and that the expression level of Twist1 was associated with the degree of tumor heterogeneity. Furthermore, tumor types with high malignancy and invasiveness frequently exhibit upregulated Twist1 expression (31). The results of the present demonstrated that Twistl was important in the occurrence and development of astrocytoma. 
A

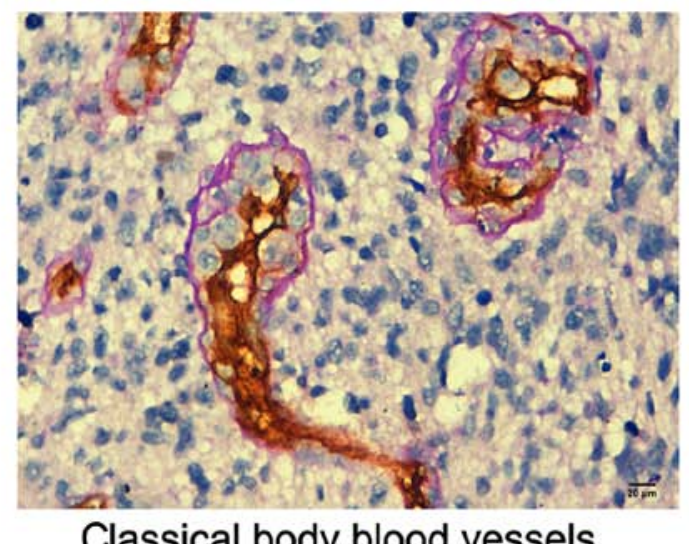

Classical body blood vessels

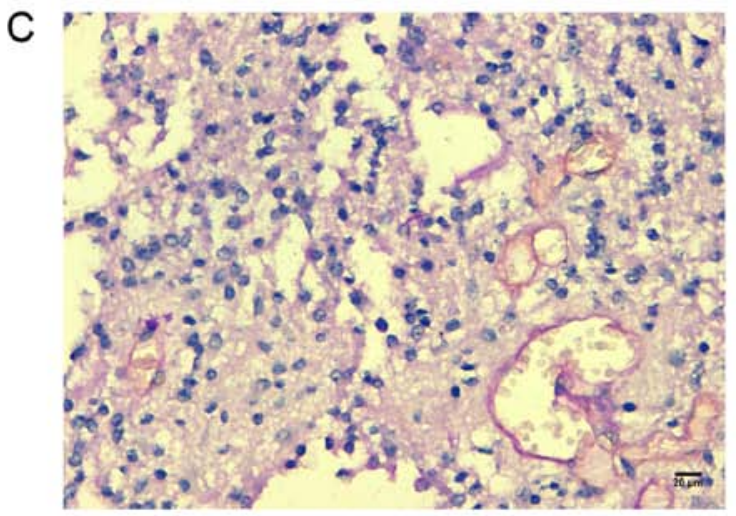

VM vessels
$\mathrm{B}$

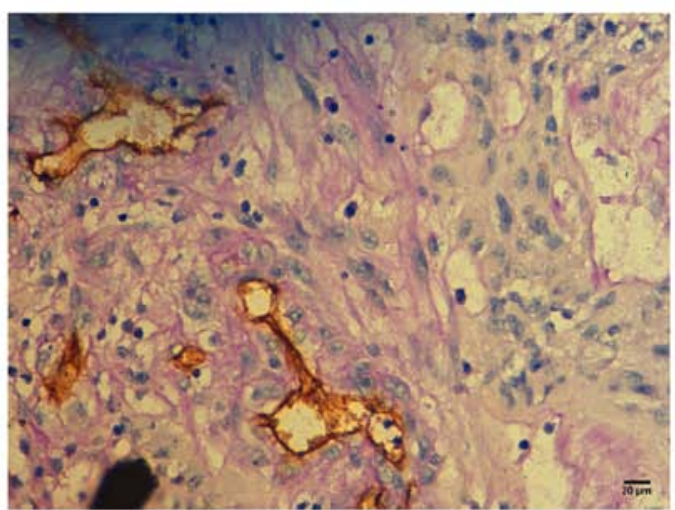

Classical body blood vessels +VM vessels

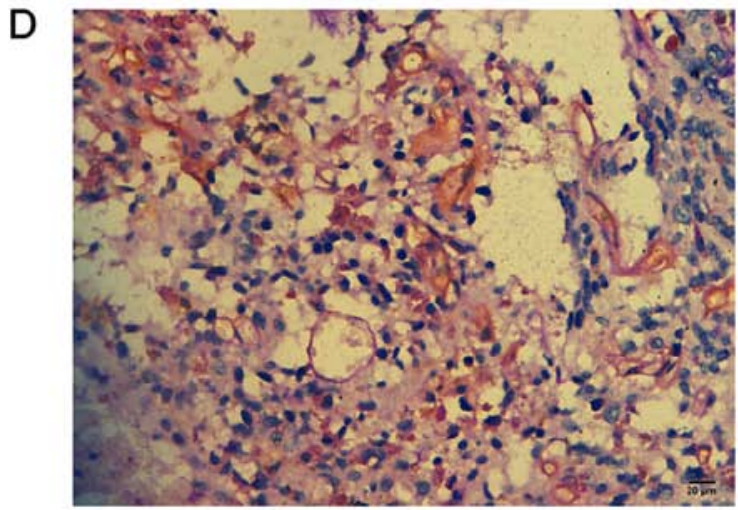

VM vessels

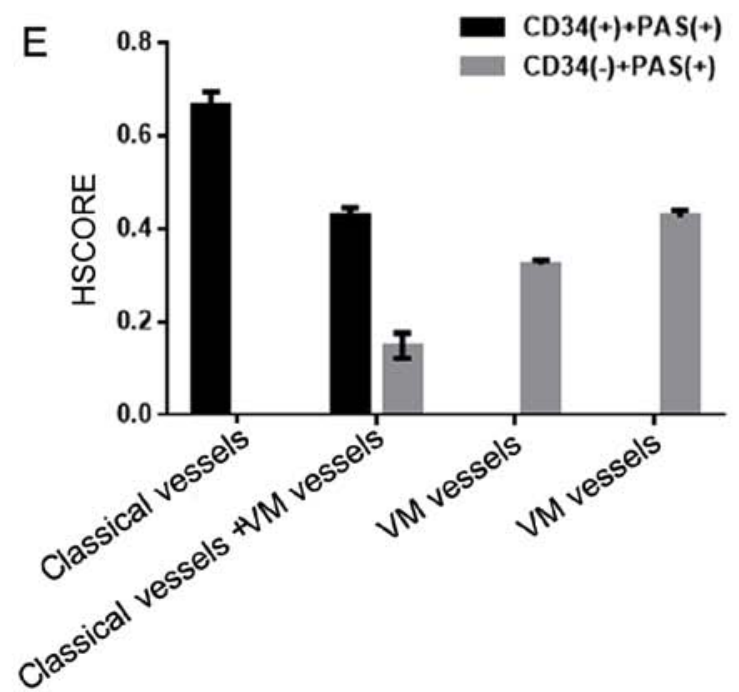

Figure 2. Association between the expression levels of Twist1 and the formation of VM. Micro-vessel proliferation $\left(\mathrm{CD}^{+} 4^{+} / \mathrm{PAS}^{+}\right)$in tumor tissues was observed using immunohistochemical and PAS staining. (A) Detection of CD34+ endothelial cells (brown) and PAS staining of the basal membrane of normal blood vessel vasculature (pink). (B) Micro-vessel proliferation $\left(\mathrm{CD}^{+} 4^{+} / \mathrm{PAS}^{+}\right)$and $\mathrm{VM}$ vessels $\left(\mathrm{CD}^{-} / \mathrm{PAS}^{+}\right)$in tumor tissues. (C) VM vessels $\left(\mathrm{CD}^{2} / \mathrm{PAS}^{+}\right)$ in tumor tissues were observed by staining anaplastic astrocytomas. (D) VM vessels (CD34-/PAS ${ }^{+}$) in tumor tissues were observed by staining glioblastomas. Magnification, x400. (E) HSCOREs of (A-D). HSCORE, histological score; CD, cluster of differentiation; PAS, Periodic Acid Schiff; VM, vasculogenic mimicry.

VM has been identified in a number of malignant tumors, including uveal melanoma and ovarian cancer (32). VM is not only associated with tumor growth, metastasis and other biological functions, but also with the prognosis of patients with tumors (33).
Studies have also demonstrated that in hepatocellular carcinoma cells, Twist 1 can promote VM by upregulating the expression levels of VE-cadherin and MMP-2/9, whilst downregulating that of E-cadherin $(8,34)$. The present study revealed that Twistl was associated with the formation of VM 
A

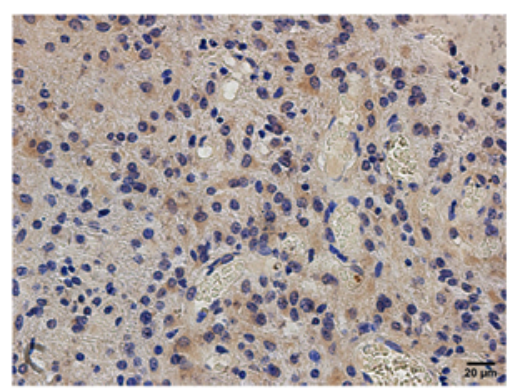

Diffuse astrocytoma
B

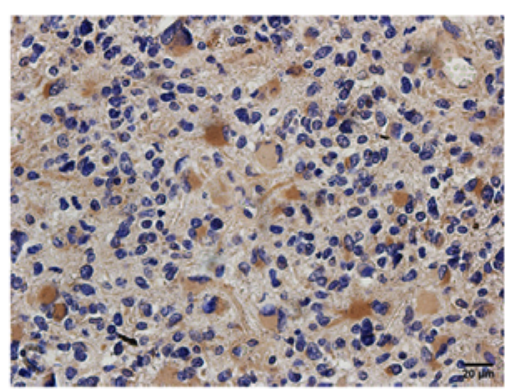

Anaplastic astrocytomas
C

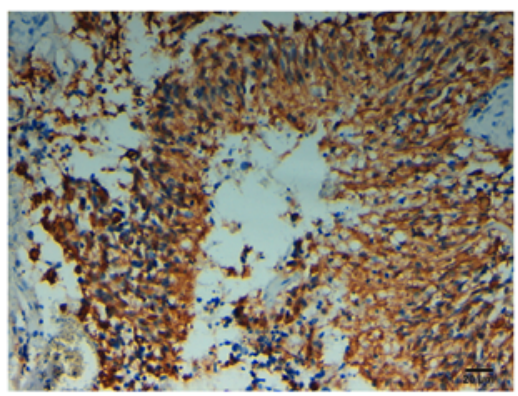

Glioblastoma

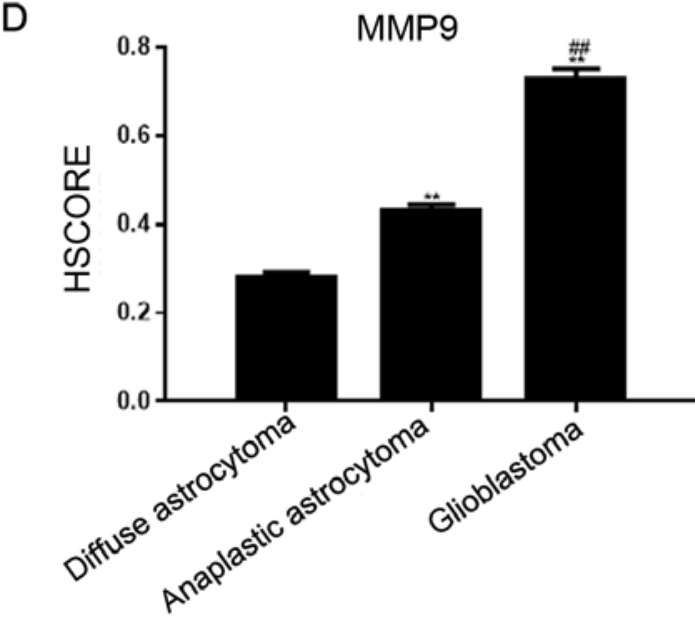

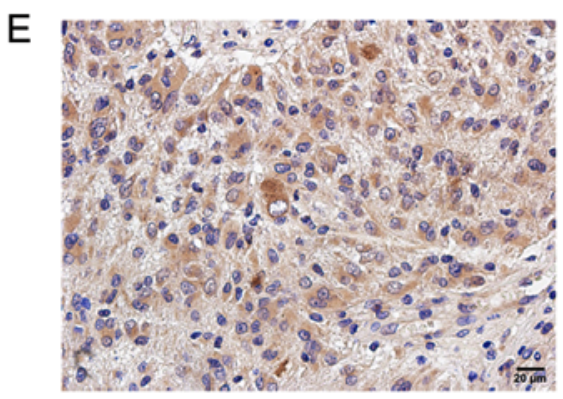

Diffuse astrocytoma

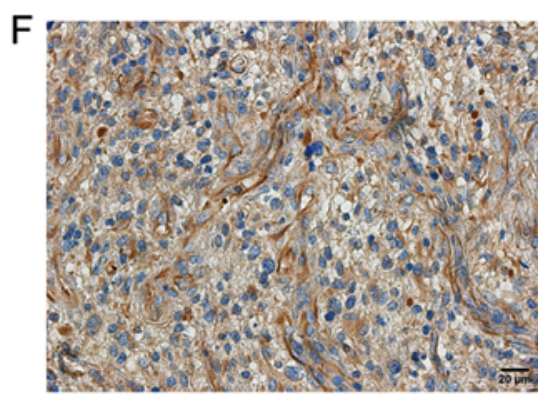

Anaplastic astrocytomas

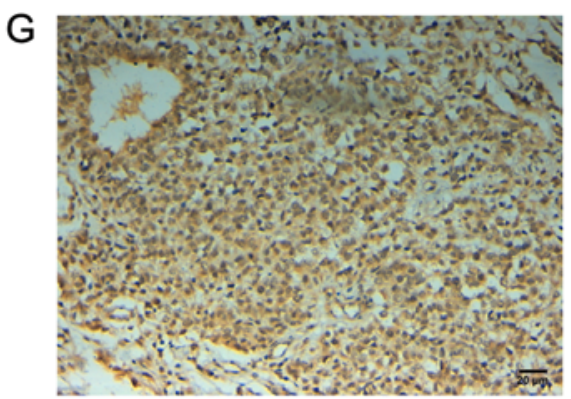

Glioblastoma

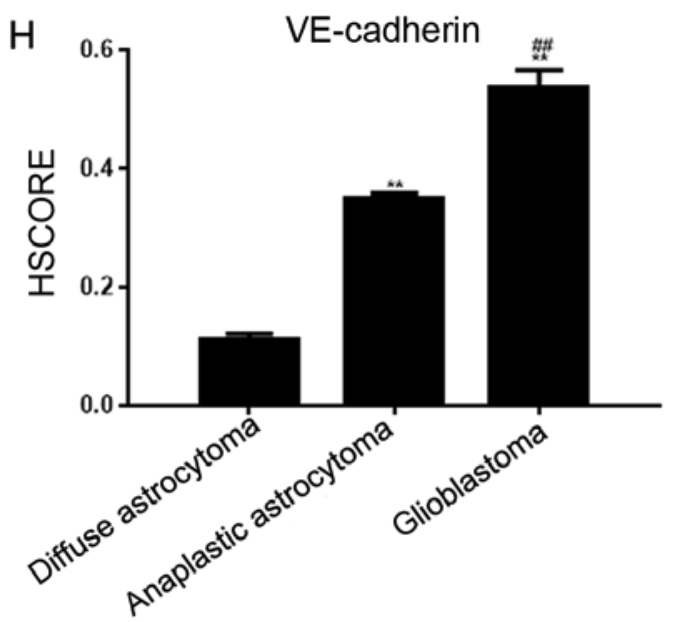

Figure 3. Expression of VE-cadherin and MMP-9 in astrocytoma tissues. (A) Diffuse and (B) anaplastic astrocytomas exhibited weak positive staining for MMP-9. (C) MMP-9 was strongly expressed in glioblastoma tissues. (D) HSCORE of (A-C) (E) VE-cadherin was weakly positive in diffuse astrocytomas, (F) VE-cadherin was moderately expressed in anaplastic astrocytomas and (G) VE-cadherin was strongly expressed in glioblastoma tissues. Both VE-cadherin and MMP-9 were located in the cytoplasm of tumor tissues and vascular endothelial cells. (H) HSCORE of (A-C) Magnification, $\mathrm{x} 200$. ${ }^{* *} \mathrm{P}<0.05$ vs. the diffuse astrocytoma group; ${ }^{\# /} \mathrm{P}<0.05$ vs. the anaplastic astrocytoma group. MMP, matrix metalloproteinase; VE, vascular endothelial; HSCORE, histological score. 


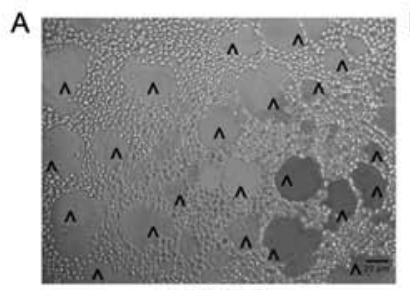

HUVEC

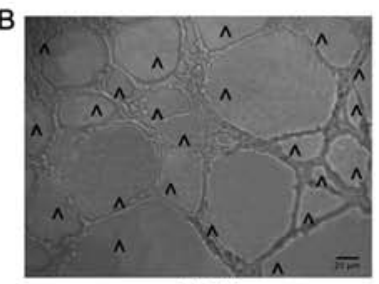

U251

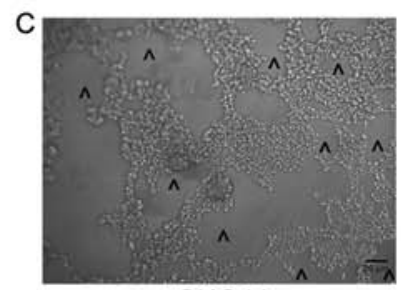

SHG44

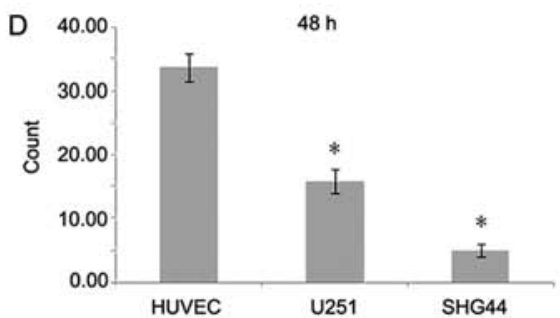

Figure 4. Formation of the cavity structure in vitro. The formation of a (A) HUVEC, (B) U251 cell and (C) SHG44 cell cavity structure in Matrigel. $\wedge^{\wedge}$ corresponds to the lumen-like structures. (D) In vitro three-dimensional culture demonstrated that the number of U251 cells forming lumen-like structures was increased compared with that in SHG44 cells. The number of lumen-like structures formed by HUVECs was greater than that of U251 and SHG44 cells. Magnification, $\mathrm{x} 100 .{ }^{*} \mathrm{P}<0.05$ vs. the HUVEC control group.
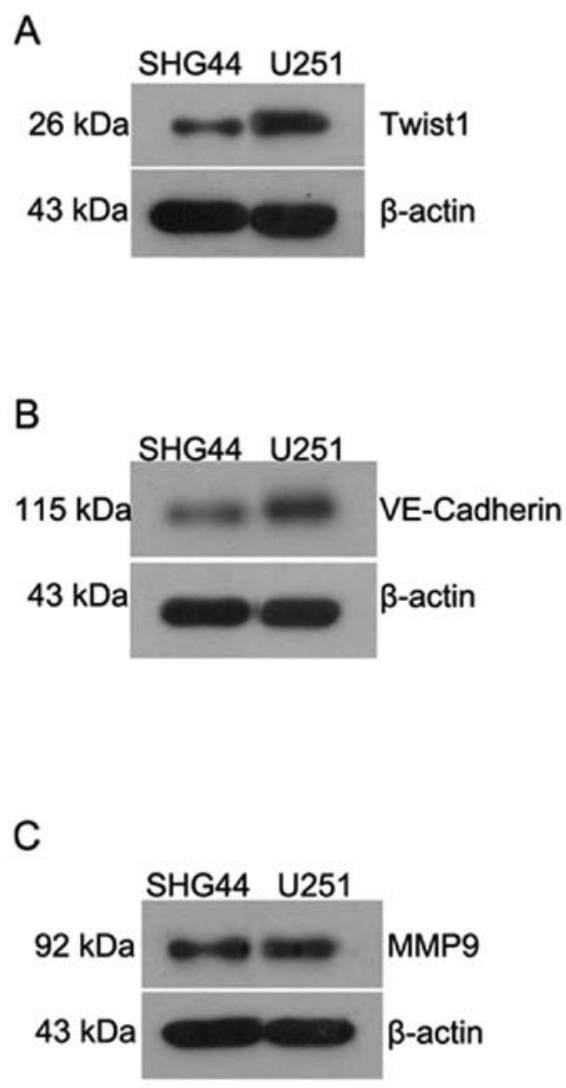
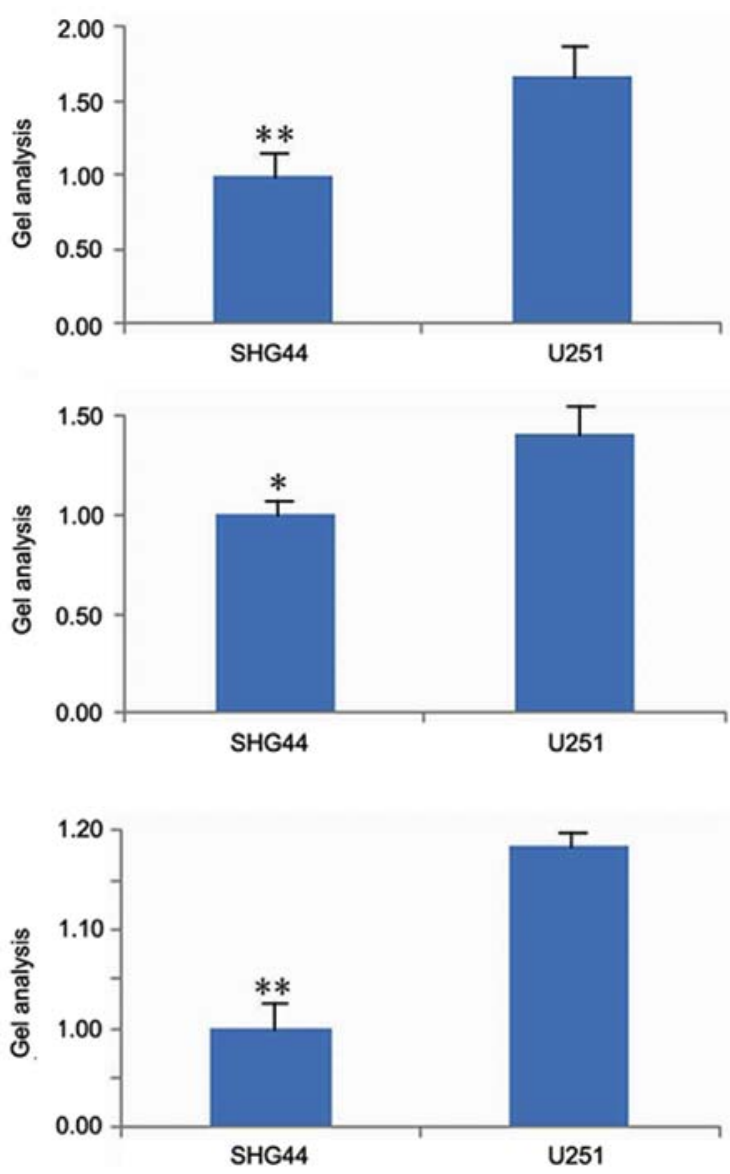

Figure 5. Expression levels of Twist1, VE-cadherin and MMP-9 proteins in U251 and SHG44 cells. Western blotting results demonstrated that (A) Twist1, (B) VE-cadherin and (C) MMP-9 expression levels in SHG44 cells were downregulated. ${ }^{*} \mathrm{P}<0.05$ and ${ }^{* *} \mathrm{P}<0.01$ vs. U251. MMP, matrix metalloproteinase; Twist1, Twist family bHLH transcription factor 1; VE, vascular endothelial.

in astrocytomas. Out of the 16 cases with VM, 15 exhibited positive expression of MMP-9. Therefore, it was concluded that MMP-9 may be involved in the formation of VM in astrocytomas. It is reported that Twist1 is able to promote tumor progression by increasing the expression of MMP-9 (35). Concurrently, it was also demonstrated that the expression of Twist1 was associated with that of MMP-9; therefore Twist1 may indirectly regulate VM via the regulation of MMP-9.

Additional studies have indicated that VE-cadherin may be a 'switch' for the induction of $\operatorname{VM}(8,36)$. The present study showed that the expression of VE-cadherin was significantly associated with the expression of Twist1 and the formation of VM in astrocytomas. Therefore, it was concluded that Twist1 and VE-cadherin may serve a synergistic role in regulating the formation of VM in astrocytomas.

Furthermore, the association between Twist 1 and the formation of cavity structures was investigated in U251 and SHG44 cells. It was revealed that both U251 and SHG44 cells formed cavity structures, and that the number of cavity structures formed by U251 cells was greater than that of SHG44 cells. In addition, it was also highlighted that the expression level of Twist1 was higher in U251 cells than in SHG44 cells, indicating that Twist 1 promoted the formation of cavity structures in U251 and SHG44 cells. 
A $\quad$ U251

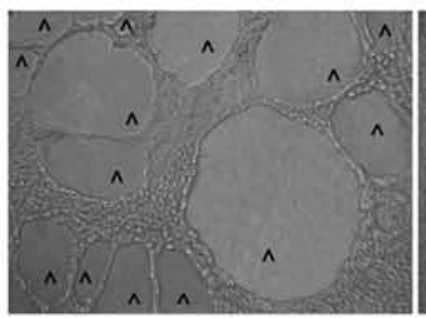

B $\mathrm{SHG}_{4}{ }^{\mathrm{con}}$

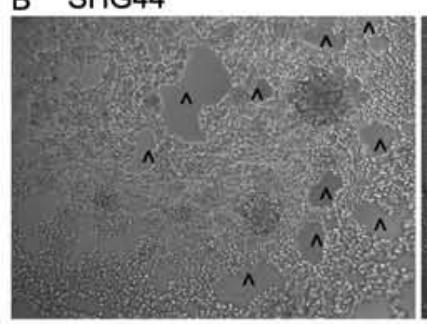

con

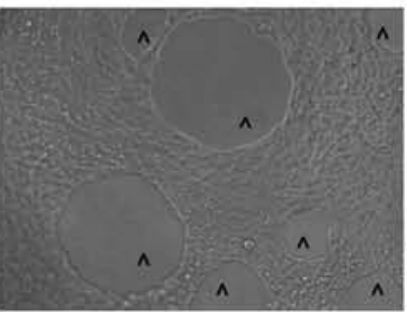

si-Twist1

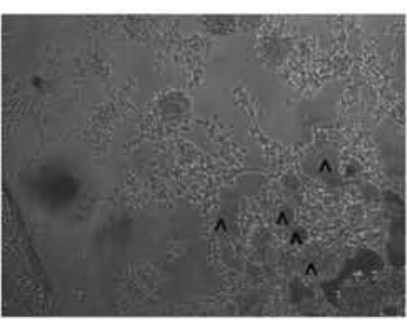

si-Twist1

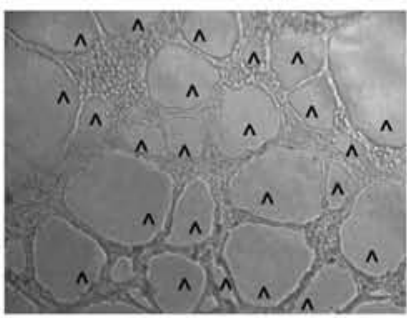

Twist1

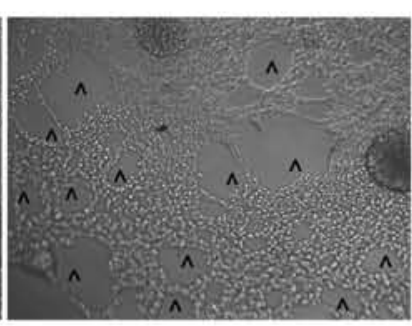

Twist1

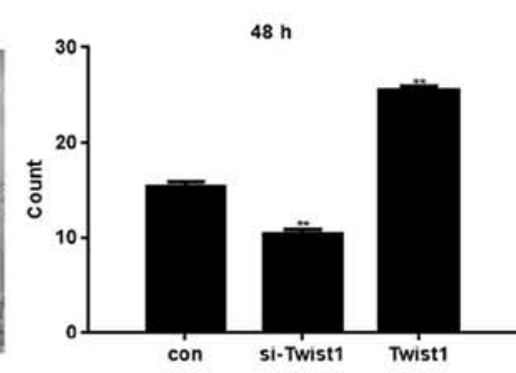

$48 \mathrm{~h}$

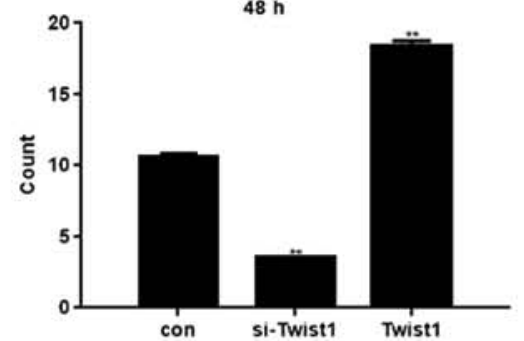

C U251
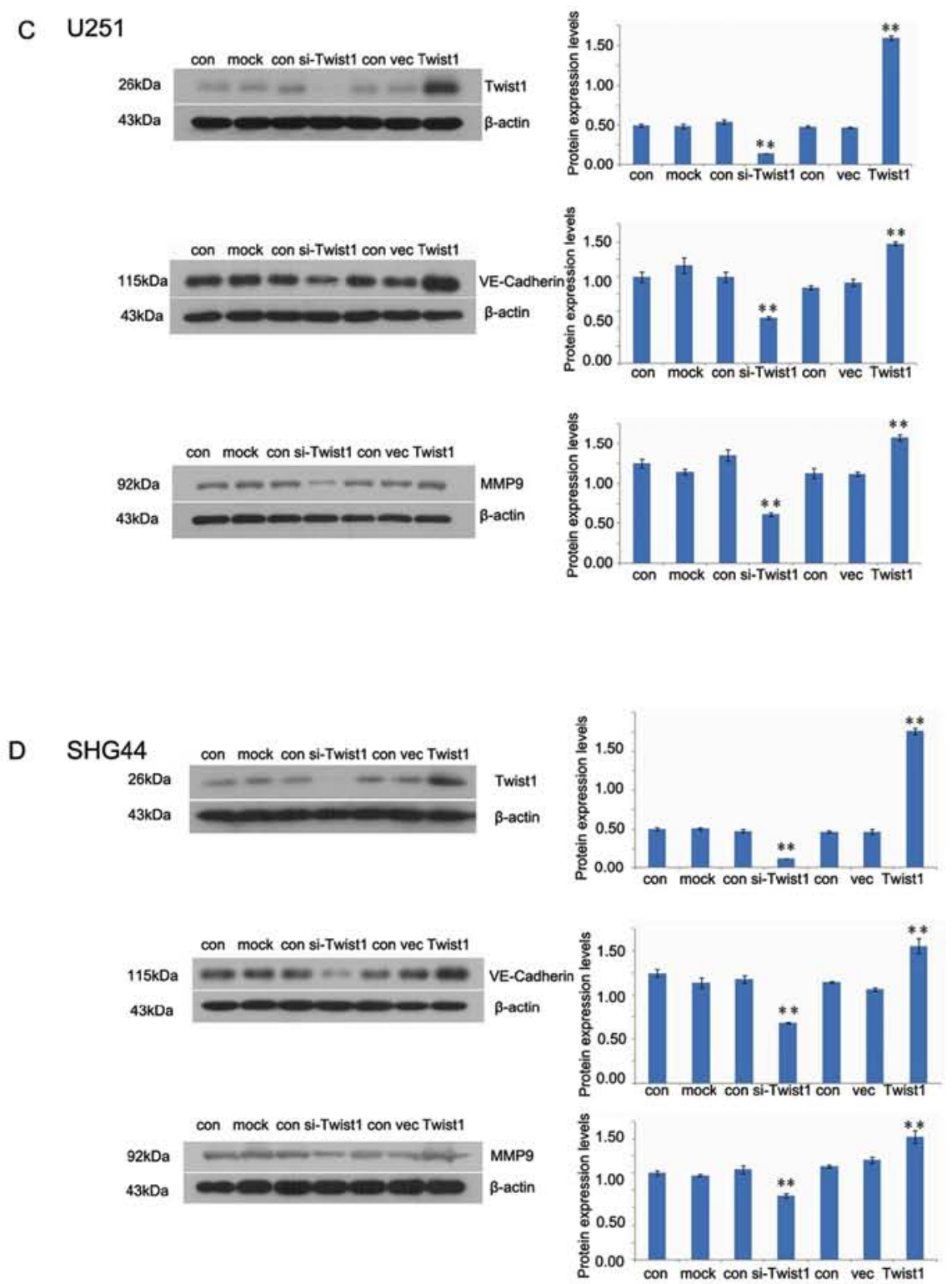

Figure 6. Effects of Twistl expression on cavity structure formation. (A) In vitro Three-dimensional culture demonstrated the number of cavity structures in (A) U251 (B) HG44 cells. ^indicates lumen-like structures. Magnification, x100. (C) Western blotting results demonstrated the expression levels of Twist1, VE-cadherin and MMP-9 proteins in (C) U251 and (D) SHG44 cells. ${ }^{* *} \mathrm{P}<0.01$ vs. the NC group. MMP, matrix metalloproteinase; VE, vascular endothelial; NC, negative control. 
The present study also revealed that the expression levels of VE-cadherin and MMP-9 in U251 cells were increased compared with those in SHG44 cells. Furthermore, the formation of VM may be associated with VE-cadherin and MMP-9. Twist1 was also shown to promote the expression of VE-cadherin and MMP-9; however, the inhibition of Twist1 decreased the expression of VE-cadherin and MMP-9. It was therefore concluded that Twist1, VE-cadherin and MMP-9 all served roles in the formation of VM in astrocytoma, and that MMP-9 and VE-cadherin are important downstream constituents, possibly targeted by Twist1 in this process.

In the present study it was determined that Twistl regulated the formation of VM in astrocytomas potentially through the Twist1/VE-cadherin/MMP-9 signaling axis. This conclusion provides a novel theoretical basis for Twist1 as a therapeutic target, presenting new insights for the targeted therapy of astrocytoma.

\section{Acknowledgements}

We would like to acknowledge the helpful comments received from our reviewers.

\section{Funding}

No funding was received.

\section{Availability of data and materials}

All data generated or analyzed during the present study are included in this published article.

\section{Authors' contributions}

WC provided the conception and design of the study, participated in all experimentation, drafted and critically revised the manuscript. CX cultured the cell lines and performed experiments. XL participated in the design of the study and experimentation. XY participated in the experiment design and the subject establishment of this article, in addition they wrote and critically revised the manuscript and gave final approval of the submitted version.

\section{Ethics approval and consent to participate}

All methods were carried out in accordance with relevant guidelines and regulations. The study protocol was approved by the Ethics Committee of the Shengjing Hospital, China Medical University and Human Clinical Trials Committee. The procedures were approved by the ethics committee according to the Chinese Community guide-lines, and written informed consent was obtained from all patients.

\section{Patient consent for publication}

Not applicable.

\section{Competing interests}

The authors declare that they have no competing interests.

\section{References}

1. Mahzouni P,Mohammadizadeh F,Mougouei K,Moghaddam NA, Chehrei A and Mesbah A: Determining the relationship between 'microvessel density' and different grades of astrocytoma based on immunohistochemistry for 'factor VIII-related antigen' (von Willebrand factor) expression in tumor microvessels. Indian J Pathol Microbiol 53: 605-610, 2010.

2. Zhang JX,ChenZH,ChenDL, TianXP,Wang CY,ZhouZW,Gao Y, Xu Y,Chen C,Zheng ZS, et al: LINC01410-miR-532-NCF2-NF-kB feedback loop promotes gastric cancer angiogenesis and metastasis. Oncogene 37: 2660-2675, 2018.

3. Huttala O, Palmroth M, Hemminki P, Toimela T, Heinonen T, Ylikomi T and Sarkanen JR: Development of versatile human in vitro vascularized adipose tissue model with serum-free angiogenesis and natural adipogenesis induction. Basic Clin Pharmacol Toxicol1 23 (Suppl): S62-S71, 2018.

4. Bao MH, Li GY, Huang XS, Tang L, Dong LP and Li JM: Long noncoding RNA LINC00657 acting as a miR-590-3p sponge to facilitate low concentration oxidized low-density lipoprotein-induced angiogenesis. Mol Pharmacol 93: 368-375, 2018.

5. Lee TJ, Shim MS, Yu T, Choi K, Kim DI, Lee SH and Bhang SH: Bioreducible polymer micelles based on acid-degradable poly(ethylene glycol)-poly(amino ketal) enhance the stromal cell-derived factor-1alpha gene transfection efficacy and therapeutic angiogenesis of human adipose-derived stem cells. Int J Mol Sci 19, 2018.

6. Yeo C, Lee HJ and Lee EO: Serum promotes vasculogenic mimicry through the EphA2/VE-cadherin/AKT pathway in PC-3 human prostate cancer cells. Life Sci 221: 267-273, 2019.

7. Guo J, Cai H, Liu X, Zheng J, Liu Y, Gong W, Chen J, Xi Z and Xue Y: Long non-coding RNA LINC00339 stimulates glioma vasculogenic mimicry formation by regulating the miR-539-5p/ TWIST1/MMPs Axis. Mol Ther Nucleic Acids 10: 170-186, 2018.

8. Yang J, Zhu DM, Zhou XG, Yin N, Zhang Y, Zhang ZX, Li DC and Zhou J: HIF-2alpha promotes the formation of vasculogenic mimicry in pancreatic cancer by regulating the binding of Twist1 to the VE-cadherin promoter. Oncotarget 8: 47801-47815, 2017.

9. Liu K, Sun B,Zhao X, Wang X, Li Y, QiuZ, Gu Q, Dong X,Zhang Y, Wang Y and Zhao N: Hypoxia induced epithelial-mesenchymal transition and vasculogenic mimicry formation by promoting Bcl-2/Twist1 cooperation. Exp Mol Pathol 99: 383-391, 2015.

10. Yue WY and Chen ZP: Does vasculogenic mimicry exist in astrocytoma? J Histochemi Cytochem 53: 997-1002, 2005.

11. Chang Z, Cui J and Song Y: Long noncoding RNA PVT1 promotes EMT via mediating microRNA-186 targeting of Twist1 in prostate cancer. Gene 654: 36-42, 2018.

12. Gou W, Zhou X, Liu Z, Wang L, Shen J, Xu X, Li Z, Zhai X, Zuo D and Wu Y: CD74-ROS1 G2032R mutation transcriptionally up-regulates Twist1 in non-small cell lung cancer cells leading to increased migration, invasion, and resistance to crizotinib. Cancer Lett 422: 19-28, 2018.

13. Grither WR, Divine LM, Meller EH, Wilke DJ, Desai RA Loza AJ, Zhao P, Lohrey A, Longmore GD and Fuh KC: TWIST1 induces expression of discoidin domain receptor 2 to promote ovarian cancer metastasis. Oncogene 37: 1714-1729, 2018.

14. Hu J, Tian J, Zhu S, Sun L, Yu J, Tian H, Dong Q, Luo Q, Jiang N, Niu Y and Shang Z: Sox5 contributes to prostate cancer metastasis and is a master regulator of TGF-beta-induced epithelial mesenchymal transition through controlling Twist1 expression. British J Cancer 118: 88-97, 2018.

15. Jianwei Z, Qi L, Quanquan X, Tianen W and Qingwei W: TMPRSS4 upregulates TWIST1 expression through STAT3 activation to induce prostate cancer cell migration. Pathol Oncol Res 24: 251-257, 2018.

16. Liu K, Sun B, Zhao X, Wang X, Li Y, Qiu Z, Liu T, Gu Q, Dong X, Zhang Y, et al: Hypoxia promotes vasculogenic mimicry formation by the Twist1-Bmil connection in hepatocellular carcinoma. Int J Mol Med 36: 783-791, 2015.

17. Sun J, Sun B, Sun R, Zhu D, Zhao X, Zhang Y, Dong X, Che N, Li J, Liu F, et al: HMGA2 promotes vasculogenic mimicry and tumor aggressiveness by upregulating Twist1 in gastric carcinoma. Sci Rep 7: 2229, 2017.

18. Sun T, Sun BC, Zhao XL, Zhao N, Dong XY, Che N, Yao Z, Ma YM, Gu Q, Zong WK and Liu ZY: Promotion of tumor cell metastasis and vasculogenic mimicry by way of transcription coactivation by Bcl-2 and Twist1: A study of hepatocellular carcinoma. Hepatology 54: 1690-1706, 2011. 
19. Sun T, Zhao N, Zhao XL, Gu Q, Zhang SW, Che N, Wang XH, Du J, Liu YX and Sun BC: Expression and functional significance of Twist1 in hepatocellular carcinoma: Its role in vasculogenic mimicry. Hepatology 51: 545-556, 2010.

20. Wang D, Zheng J, Liu X, Xue Y, Liu L, Ma J, He Q, Li Z, Cai H and Liu Y: Knockdown of USF1 inhibits the vasculogenic mimicry of glioma cells via stimulating SNHG16/miR-212-3p and linc00667/miR-429 Axis. Mol Ther Nucleic Acids 14: 465-482, 2019.

21. Berchuck A, Soisson AP, Clarke-Pearson DL, Soper JT, Boyer CM, Kinney RB, McCarty KS Jr and Bast RC Jr: Immunohistochemical expression of CA 125 in endometrial adenocarcinoma: Correlation of antigen expression with metastatic potential. Cancer Res 49: 2091-2095, 1989.

22. Liu Y, Li F, Yang YT, Xu XD, Chen JS, Chen TL, Chen HJ, Zhu YB, Lin JY and Li Y: IGFBP2 promotes vasculogenic mimicry formation via regulating CD144 and MMP2 expression in glioma. Oncogene 38: 1815-1831, 2019.

23. Bhogal P, Yeo LL, Henkes H, Krings T and Soderman M: The role of angiogenesis in dural arteriovenous fistulae: The story so far. Interv Neuroradiol 24: 450-454, 2018.

24. Brennan MA, Renaud A, Guilloton F, Mebarki M, Trichet V, Sensebé L, Deschaseaux F, Chevallier N and Layrolle P: Inferior in vivo osteogenesis and superior angiogenesis of human adipose-derived stem cells compared with bone marrow-derived stem cells cultured in xeno-free conditions. Stem Cells Trans Med 7: 315, 2018.

25. Carbone C, Piro G, Merz V, Simionato F, Santoro R, Zecchetto C, Tortora G and Melisi D: Angiopoietin-like proteins in angiogenesis, inflammation and cancer. Int J Mol Sci 19, 2018.

26. Casas BS, Vitoria G, do Costa MN, Madeiro da Costa R, Trindade P, Maciel R, Navarrete N, Rehen SK and Palma V: hiPSC-derived neural stem cells from patients with schizophrenia induce an impaired angiogenesis. Transl Psychiatry 8: 48, 2018.

27. Rahme GJ and Israel MA: Id4 suppresses MMP2-mediated invasion of glioblastoma-derived cells by direct inactivation of Twistl function. Oncogene 34: 53-62, 2015.
28. Mikheeva SA, Mikheev AM, Petit A, Beyer R, Oxford RG, Khorasani L, Maxwell JP, Glackin CA, Wakimoto $H$, González-Herrero I, et al: TWIST1 promotes invasion through mesenchymal change in human glioblastoma. Mol Cancer 9: 194, 2010.

29. Yoon NA, Jo HG, Lee UH, Park JH, Yoon JE, Ryu J, Kang SS, Min YJ, Ju SA, Seo EH, et al: Tristetraprolin suppresses the EMT through the down-regulation of Twistl and Snaill in cancer cells. Oncotarget 7: 8931-8943, 2016.

30. Pecina-Slaus N, Kafka A, Tomas D, Marković L, Okštajner PK, Sukser V and Krušlin B: Wnt signaling transcription factors TCF-1 and LEF-1 are upregulated in malignant astrocytic brain tumors. Histol Histopathol 29: 1557-1564, 2014.

31. Wang L, Lin L, Chen X, Sun L, Liao Y, Huang N and Liao W: Metastasis-associated in colon cancer-1 promotes vasculogenic mimicry in gastric cancer by upregulating TWIST1/2 Oncotarget 6: 11492-11506, 2015.

32. Zhang D, Sun B, Zhao X, Ma Y, Ji R, Gu Q, Dong X, Li J, Liu F, Jia $X$, et al: Twist1 expression induced by sunitinib accelerates tumor cell vasculogenic mimicry by increasing the population of CD133+ cells in triple-negative breast cancer. Mol Cancer 13: 207, 2014.

33. Tian W, Li YS, Zhang JH, Li JJ and Gao JH: Comprehensive analysis of DNA methylation and gene expression datasets identified MMP9 and TWIST1 as important pathogenic genes of lung adenocarcinoma. DNA Cell Biol 37: 336-346, 2018.

34. Han H, Du L, Cao Z, Zhang B and Zhou Q: Triptonide potently suppresses pancreatic cancer cell-mediated vasculogenic mimicry by inhibiting expression of VE-cadherin and chemokine ligand 2 genes. Eur J Pharmacol 818: 593-603, 2018.

35. Liu W, Lv C, Zhang B, Zhou Q and Cao Z: MicroRNA-27b functions as a new inhibitor of ovarian cancer-mediated vasculogenic mimicry through suppression of VE-cadherin expression. RNA 23: 1019-1027, 2017.

36. Delgado-Bellido D, Serrano-Saenz S, Fernandez-Cortes M and Oliver FJ: Vasculogenic mimicry signaling revisited: Focus on non-vascular VE-cadherin. Mol Cancer 16: 65, 2017. 